Bài báo khoa học

\title{
Phát thải khí nhà kính trong tiểu lĩnh vực trồng trọt và chăn nuôi tại tỉnh Quảng Nam giai đoạn 2010-2018
}

\author{
Lê Ánh Ngọc ${ }^{1}$, Phạm Đức Ân ${ }^{1}$, Phạm Thanh Long ${ }^{*}$, Nguyễn Thị Liễu ${ }^{2}$, Đoàn Quang \\ Trí $^{3}$ \\ ${ }^{1}$ Phân viện Khoa học Khí tượng Thủy văn và Biến đổi khí hậu; \\ leanhngoc.sihymete@gmail.com; phamthanhlong559@gmail.com \\ ${ }^{2}$ Viện Khoa học Khí tượng Thủy văn và Biến đổi khí hậu; lieuminh2011@gmail.com \\ ${ }^{3}$ Tạp chí Khí tượng Thủy văn, Tổng cục khí tượng Thủy văn; doanquangtrikttv@gmail.com \\ * Tác giả liên hệ: phamthanhlong559@gmail.com; Tel.: +84-905779777
}

Ban Biên tập nhận bài: 05/11/2020; Ngày phản biện xong: 10/12/2020; Ngày đăng bài: $25 / 12 / 2020$

Tóm tắt: Bài báo trình bày kết quả tính toán phát thải khí nhà kính tại tỉnh Quảng Nam, một tỉnh thuộc vùng kinh tế trọng điểm miền Trung trong lĩnh vực chăn nuôi và trồng trọt (không bao gồm phát thải và hấp thụ từ đất, cũng như đốt $\sinh$ khối từ đất rừng và chuyển đổi sử dụng của đất rừng) giai đoạn 2010-2018 theo Hướng dẫn kiểm kê quốc gia khí nhà kính 2006. Theo đó, tổng lượng phát thải khí nhà kính trong lĩnh vực trồng trọt và chăn nuôi tại tỉnh Quảng Nam trong giai đoạn 2010-2018 là 16.251,74 $\mathrm{GgCO}_{2}$ tđ và có xu hướng tăng dần từ 1.792,55 $\mathrm{GgCO}_{2}$ tđ (năm 2010) lên 1.829,52 $\mathrm{GgCO}_{2}$ tđ (năm 2018). Năm có lượng phát thải lớn nhất là năm $2018\left(1.829,52 \mathrm{GgCO}_{2}\right.$ tđ) và năm có lượng phát thải thấp nhất là năm $2013\left(1.766,96 \mathrm{GgCO}_{2}\right.$ tđ). Về cơ cấu phát thải, lĩnh vực chăn nuôi chiếm tỉ lệ $25,38 \%$ và lĩnh vực trồng trọt chiếm $74,62 \%$.

Từ khóa: Phát thải khí nhà kính; Nông nghiệp; ALU; IPCC.

\section{Mở đầu}

Kế hoạch hành động về ứng phó với biến đổi khí hậu $(\mathrm{BĐKH)} \mathrm{của} \mathrm{mỗi} \mathrm{tỉnh/thành} \mathrm{phố}$ bắt đầu bằng việc thực hiện công tác kiểm kê khí nhà kính. Mục đích của việc kiểm kê phát thải khí nhà kính có thể giúp các nhà quản lý hiểu mức đóng góp phát thải từ các ngành khác nhau từ đó xây dựng kịch bản phát thải trong tương lai, thiết lập mục tiêu giảm phát thải KNK dựa trên các căn cứ cụ thể, là căn cứ để hỗ trợ việc xây dựng, thực hiện và theo dõi các chính sách và hành động giảm phát thải KNK và ứng phó với $\mathrm{BĐKH.} \mathrm{Đồng} \mathrm{thời,} \mathrm{thông} \mathrm{qua} \mathrm{kiểm} \mathrm{kê}$ khí nhà kính nhằm so sánh, học hỏi và chia sẻ kinh nghiệm với các tỉnh/thành phố khác.

Hướng dẫn IPCC 2006 về Kiểm kê khí nhà kính quốc gia được đưa ra trên cơ sở đề xuất của Công ước khung của Liên hợp quốc về Biến đổi khí hậu (UNFCCC) để cập nhật Hướng dẫn sửa đổi năm 1996 và Hướng dẫn thực hành tốt liên quan nhằm cung cấp các phương pháp luận được quốc tế đồng ý sử dụng các quốc gia các tỉnh/thành phố ước tính lượng phát thải khí nhà kính để báo cáo cho quốc gia cũng như UNFCCC [1].

Hiện nay trên thế giới và trong khu vực đã có 09 quốc gia sử dụng phần mềm $A L U$ với hướng dẫn IPCC 2006 để kiểm kê khí nhà kính đó là Cam-pu-chia, In-đô-nê-xi-a, Lào, Ma-lai-xi-a, Phi-líp-pin, Xinh-ga-po, Thái Lan, Việt Nam và Pa-pu Niu-ghi-nê. Phần mềm ALU là một công cụ hướng dẫn người dùng quy trình ước tính lượng phát thải và hấp thụ khí nhà kính quốc gia liên quan đến các hoạt động nông nghiệp và lâm nghiệp. Phần mềm đơn 
giản hóa quá trình tiến hành kiểm kê bằng cách chia quá trình phân tích kiểm kê thành các bước để tạo điều kiện thuận lợi cho việc nhập dữ liệu hoạt động, ấn định hệ số thay đổi phát thải. Phần mềm tương thích với Hướng dẫn kiểm kê KNK quốc gia năm 2006 của IPCC trong lĩnh vực Nông nghiệp, Lâm nghiệp và Sử dụng đất khác. Đồng thời, phần mềm liên kết kiểm kê KNK với việc lập kế hoạch và phát triển các hành động giảm thiểu hữu ích trong việc phát triển các Hành động Giảm thiểu Phù hợp Quốc gia và Chiến lược Phát triển Phát thải Thấp [2-4].

Sau khi Thỏa thuận Paris về biến đổi khí hậu được thông qua tại COP21 ràng buộc trách nhiệm của tất cả các bên trong công tác cắt giảm phát thải khí nhà kính, Các hoạt động giảm nhẹ đã được đưa vào Báo cáo Đóng góp do quốc gia tự quyết định (NDC). Để có thể triển khai thành công các hoạt động giảm nhẹ này, các quốc gia cũng như các bộ/ngành và địa phương cần thiết phải có hệ thống kiểm kê phát thải KNK chi tiết từ đó kiểm kê hiện trạng phát thải khí nhà kính và xây dựng kịch bản phát thải cơ sở và kịch bản phát thải giảm nhẹ.

Năm 2019, thành phố Hà Nội hiện đã thực hiện kiểm kê khí nhà kính, tập trung vào 2 lĩnh vực: Chất thải và năng lượng. Đối với nhiệm vụ này, công việc kiểm kê khí nhà kính được thực hiện theo phần mềm ALU với hướng dẫn của IPCC 2006. Trong đó, phát thải khí nhà kính từ các bãi chôn lấp khoảng 2,35 triệu tấn $\mathrm{CO}_{2}$ tương đương (chiếm $57,97 \%$ tổng phát thải khí nhà kính trên địa bàn thành phố) là hoạt động phát thải khí nhà kính nhiều nhất. Đối với lĩnh vực năng lượng, dự báo đến năm 2020, phát thải khí nhà kính trên toàn Thành phố tăng lên đến 18,2 triệu tân $\mathrm{CO}_{2}$ tương đương và đến năm 2030 con số này tăng lên đến 42,7 triệu tấn (tức tăng lên hơn 3 lần so với mức phát thải năm 2015) [5].

Năm 2103, thành phố Đà Nẵng phối hợp với Cơ quan phát triển Pháp (AFD) thực hiện dự án "Kế hoạch hành động ứng phó biến đồi khí hậu trên địa bàn thành phố". Trong dự án này đã thực hiện kiểm kê khí nhà kính theo phần mềm ALU với Hướng dẫn IPCC 2006 cho lĩnh vực Năng lượng, tập trung vào tiêu thu điện sinh hoạt. Lượng phát thải khí nhà kính trong hạng mục này của Đà Nẵng năm 2010 là 1,54 triệu tấn $\mathrm{CO}_{2}$ quy đổi, trong đó có 280 nghìn tấn $\mathrm{CO}_{2}$ quy đổi cho lĩnh vực hộ gia đình và 80 nghìn tấn $\mathrm{CO}_{2}$ quy đổi lĩnh vực dịch vụ. Dự báo đến năm 2025 , lượng $\mathrm{CO}_{2}$ sẽ tăng lên 1.368 nghìn tấn, do đó, cần phải giảm đáng kể trong lĩnh vực gia đình và dịch vụ để kiểm soát phát khí thải nhà kính ở mức cơ sở năm 2010 [6].

Trong dự án "Hỗ trợ lên kế hoạch và thực hiện các hành động giảm nhẹ phát thải khí nhà kính phù hợp với điều kiện quốc gia" của thành phố Hồ Chí Minh được thực hiện với sự hỗ trợ từ Cơ Quan Hợp Tác Quốc Tế Nhật Bản (JICA) năm 2019 trong đó có nội dụng kiểm kê khí nhà kính cho năm cơ sở 2013. Đây là lần kiểm kê KNK toàn diện đầu tiên của Thành phố Hồ Chí Minh. Phát thải KNK của Tp. $\mathrm{HCM}$ là 38,5 triệu tấn $\mathrm{CO}_{2}$ tương đương. chiếm $16 \%$ lượng phát thải quốc gia. Trong lần kiểm kê này, hướng dẫn IPCC 2006 được sử dụng để tính toán phát thải khí nhà kính cho thành phố Hồ Chí Minh [7-8]. Ngoài ra, một vài thành phố lớn như Hải Phòng, Đồng Nai cũng đã bước đầu tiến hành kiểm kê khí nhà kính các lĩnh vực nhằm đánh giá hiện trạng phát thải khí nhà kính của địa phương theo đúng Hướng dẫn của IPCC 2006.

Phầm mềm ALU (Agricultural Land Used Management) là phần mềm được phát triển bởi Giáo sư Stephen Ogle và cộng sự tại Đại học bang Colorado theo một thỏa thuận tài trợ của Cơ quan Bảo vệ Môi trường Hoa Kỳ và Sở Nông Lâm nghiệp dùng để kiểm kê khí nhà kính trong nông nghiệp, lâm nghiệp và sử dụng đất. ALU được phát triển dựa trên hướng dẫn IPCC năm 1996, hướng dẫn IPCC năm 2000, hướng dẫn IPCC năm 2003 và hướng dẫn IPCC năm 2006 để phù hợp với các tiêu chuẩn quốc tế chính thức. Trong nghiên cứu, chúng tôi đã sử dụng phiên bản cập nhật ALU Software-Version 6.0.1 (31-01-2018) tuân thủ các phương pháp tính toán theo đúng hướng dẫn IPCC 2006 (Hình 1) [2-4]. 


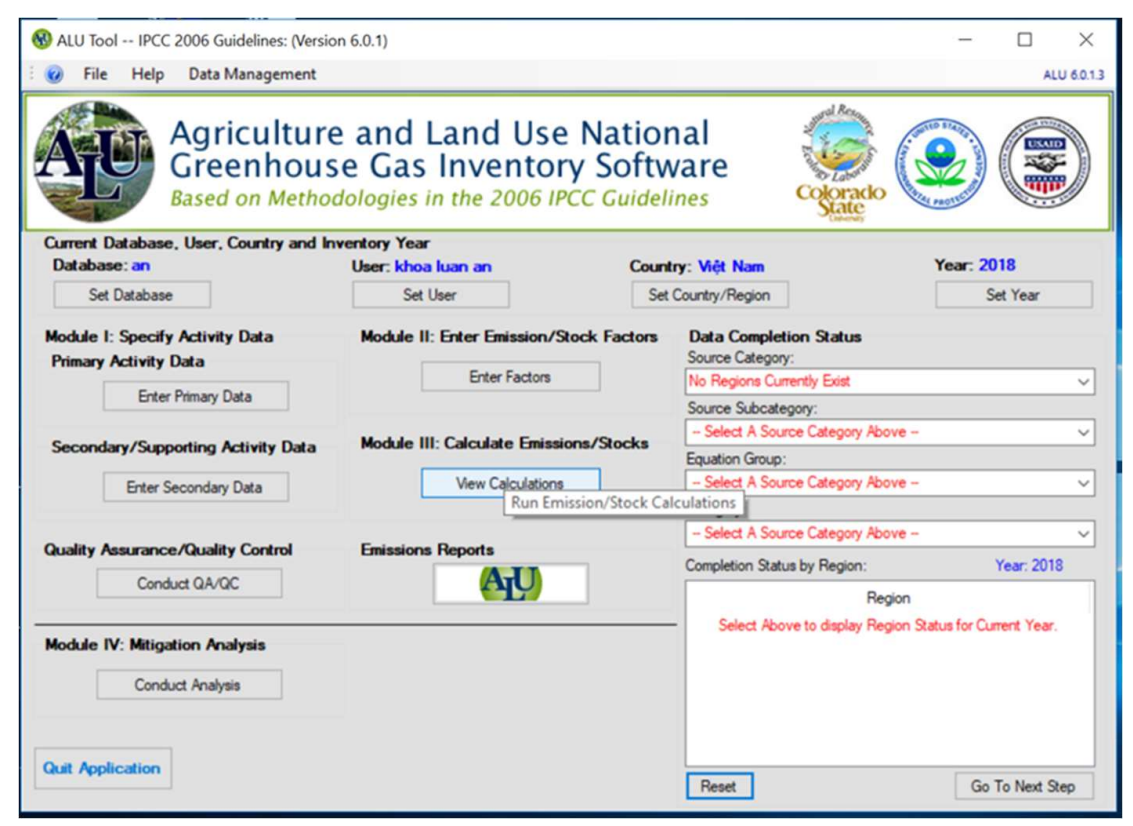

Hình 1. Giao diện phần mềm kiểm kê khí nhà kính ALU phiên bản 6.0.1.

Trong nghiên cứu này sẽ sử dụng phần mềm ALU để tính toán phát thải khí nhà kính trong lĩnh vực chăn nuôi và trồng trọt với số liệu hoạt động giai đoạn 2010-2018 tại tỉnh Quảng Nam. Số liệu đầu vào cho phần mềm ALU là số liệu hoạt động cho tính toán phát thải theo từng tiểu lĩnh vực bao gồm: Tiêu hóa thức ăn, Quản lý chất thải, Đốt sinh khối trong trồng trọt, Bón vôi cho đất nông nghiệp, Bón phân ure, Phát thải trực tiếp $\mathrm{N}_{2} \mathrm{O}$ từ đất, Phát thải gián tiếp $\mathrm{N}_{2} \mathrm{O}$ từ đất, Phát thải gián tiếp $\mathrm{N}_{2} \mathrm{O}$, Canh tác lúa.

Đối với tiểu lĩnh vực Tiêu hóa thức ăn số liệu hoạt động là số lượng các vật nuôi bao gồm Bò sữa, Bò thịt, Trâu, Dê, Ngựa, Lợn giai đoạn 2010-2018. Đối với tiểu lĩnh vực Quản lý chất thải và phát thải gián tiếp $\mathrm{N}_{2} \mathrm{O}$ thì sổ liệu hoạt động là số lượng các loại vật nuôi tương tự số liệu dùng trong tiểu lĩnh vực Tiêu hóa thức ăn. Một thông số quan trọng cẩn chú ý đối với hạng mục này là tỷ lệ về hệ thống quản lý chất thải vật nuôi theo từng năm. Ngoài ra, việc thống kề lượng phân bón dùng cho nông nghiệp là một số liệu cần được thống kê chính xác theo từng năm.

Tiều lĩnh Đốt sinh khối từ đất trồng trọt cũng như tiểu lĩnh vực phát thải trực tiếp và gián tiếp $\mathrm{N}_{2} \mathrm{O}$ từ đất thì số liệu hoạt động là sản lượng, năng suất và diện tích các loại cây trông hàng năm. Tiểu lĩnh vực Bón phân ure và Bón vôi cho đất nông nghiệp thì lượng phân ure và lượng vôi bón cho cây trông là số liệu hoạt động để tính toán phát thải. Tiểu lĩnh vực Canh tác lúa thì số liệu hoạt động là diện tích lúa canh tác hàng năm theo từng loại hình quản lý nước (ví dụ: lúa tưới ngập thường xuyên, lúa tưới ngập nước một phần, lúa tưới ngập toàn phần...).

\section{Hiện trạng một số tiểu lĩnh vực trong lĩnh vực nông nghiệp tại tỉnh Quảng Nam}

\subsection{Trồng trọt}

Lúa là cây trồng chiếm diện tích khá lớn so với các loại cây hàng năm tại Quảng Nam (chiếm 87,6\% năm 2018). Diện tích trồng lúa tại Quảng Nam không thay đổi nhiều trong giai đoạn năm 2010-2018. Mặc dù đang áp dụng chính sách chuyển cơ cấu ngành nông nghiệp sang công nghiệp nhưng diện tích trồng lúa vẫn được giữ nguyên và có phần tăng nhẹ trong thời gian qua. Nguyên nhân chính do thóc luôn chiếm tỷ trọng cao trong tổng sản lượng lương thực của tỉnh (89,1\% vào năm 2018). 
Bảng 1. Diện tích trồng lúa tại Quảng Nam giai đoạn 2010-2018 [9-11].

\begin{tabular}{cccccccccc}
\hline Năm & $\mathbf{2 0 1 0}$ & $\mathbf{2 0 1 1}$ & $\mathbf{2 0 1 2}$ & $\mathbf{2 0 1 3}$ & $\mathbf{2 0 1 4}$ & $\mathbf{2 0 1 5}$ & $\mathbf{2 0 1 6}$ & $\mathbf{2 0 1 7}$ & $\mathbf{2 0 1 8}$ \\
\hline \multirow{2}{*}{ Cả năm } & 85,3 & 87,7 & 88,6 & 87,9 & 87,4 & 88,5 & 86,7 & 86,8 & 86,3 \\
\hline
\end{tabular}

\subsection{Chăn nuôi}

Ngành chăn nuôi có bước phát triển mạnh, bước đầu chuyển từ qui mô nhỏ sang chăn nuôi gia trại, trang trại. Giai đoạn 2010-2018, đối với gia súc, heo có số lượng lớn nhất, ngựa có số lượng nhỏ nhất. Tuy nhiên, sản lượng heo có xu hướng giảm từ 574.700 (năm 2010) xuống 449.800 con (năm 2018). Trong khi đó, sản lượng gia cầm tăng cao trong giai đoạn này, từ 3.931.000 con (năm 2010) lên 6.082.000 con (năm 2018).

Bảng 2. Số lượng gia súc, gia cầm giai đoạn 2010-2018 tại tỉnh Quảng Nam [9,10,13,14].

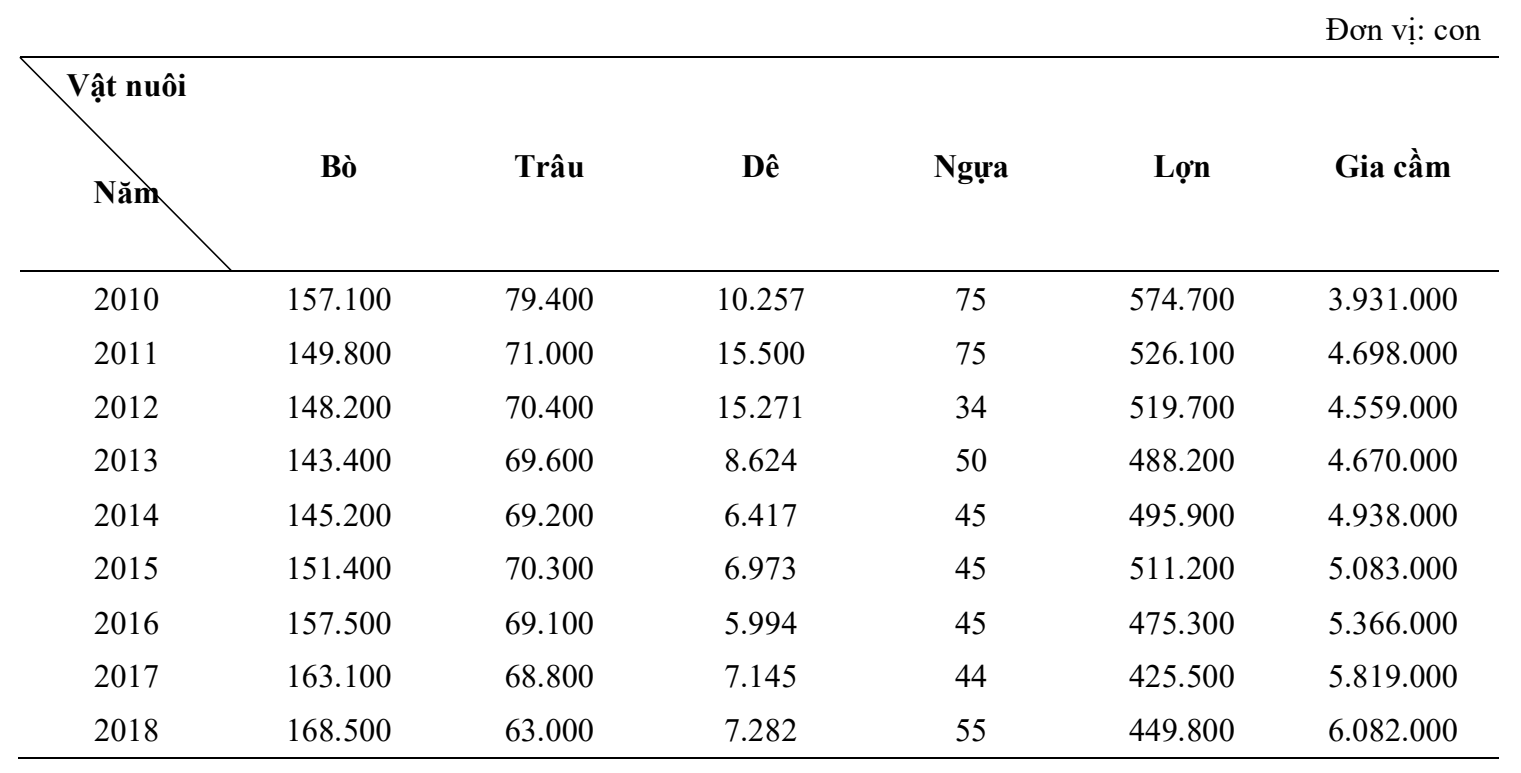

\section{Kết quả và thảo luận}

3.1. Tổng quan phát thải khí nhà kính giai đoạn 2010-2020 lĩnh vục chăn nuôi và trồng trọt tại Quảng Nam

Theo kết quả tính toán, tổng phát thải khí nhà kính lĩnh vực vực chăn nuôi và trồng trọt tỉnh Quảng Nam trong giai đoạn 2010-2018 là 16.251,74 $\mathrm{GgCO}_{2}$ tđ, nhìn chung xu thế phát thải qua các năm trong giai đoạn này thay đổi không nhiều. Theo từng tiểu lĩnh vực thì tổng phát thải từ canh tác lúa của cả giai đoạn 2010-2018 là lớn nhất (7.384,96 $\mathrm{GgCO}_{2}$ tđ), phát thải nhỏ nhất là từ bón vôi cho đất nông nghiệp $\left(6,82 \mathrm{GgCO}_{2}\right.$ tđ). Theo từng năm thì năm 2015 phát thải lớn nhất $\left(1.834,30 \mathrm{GgCO}_{2}\right.$ tđ) và năm 2013 phát thải nhỏ nhất $(1.766,96$ $\mathrm{GgCO}_{2}$ tđ). Theo cơ cấu phát thải thì trong tiểu lĩnh vực trồng trọt chiếm tỉ lệ $74,62 \%$ và tiểu lĩnh vực chăn nuôi chiếm $25,38 \%$.

Bảng 3. Tổng phát thải KNK trong ngành nông nghiệp tỉnh Quảng Nam giai đoạn 2010-2018.

\begin{tabular}{lccccccccccc} 
& \multicolumn{1}{c}{1} & \multicolumn{4}{c}{ Đơn vị: GgCO $\mathrm{G}_{2}$ đ } \\
\hline Nguồn phát thải & $\mathbf{2 0 1 0}$ & $\mathbf{2 0 1 1}$ & $\mathbf{2 0 1 2}$ & $\mathbf{2 0 1 3}$ & $\mathbf{2 0 1 4}$ & $\mathbf{2 0 1 5}$ & $\mathbf{2 0 1 6}$ & $\mathbf{2 0 1 7}$ & $\mathbf{2 0 1 8}$ & $\mathbf{2 0 1 0 - 2 0 1 8}$ \\
\hline Tổng & $1.792,55$ & $1.788,25$ & $1.791,03$ & $1.766,96$ & $1.793,03$ & $1.834,30$ & $1.825,10$ & $1.831,00$ & $1.829,52$ & $16.251,74$
\end{tabular}


Tạp chí Khi tuợng Thủy văn 2020, 720, 78-86; doi: 10.36335/VNJHM.2020(720).78-86

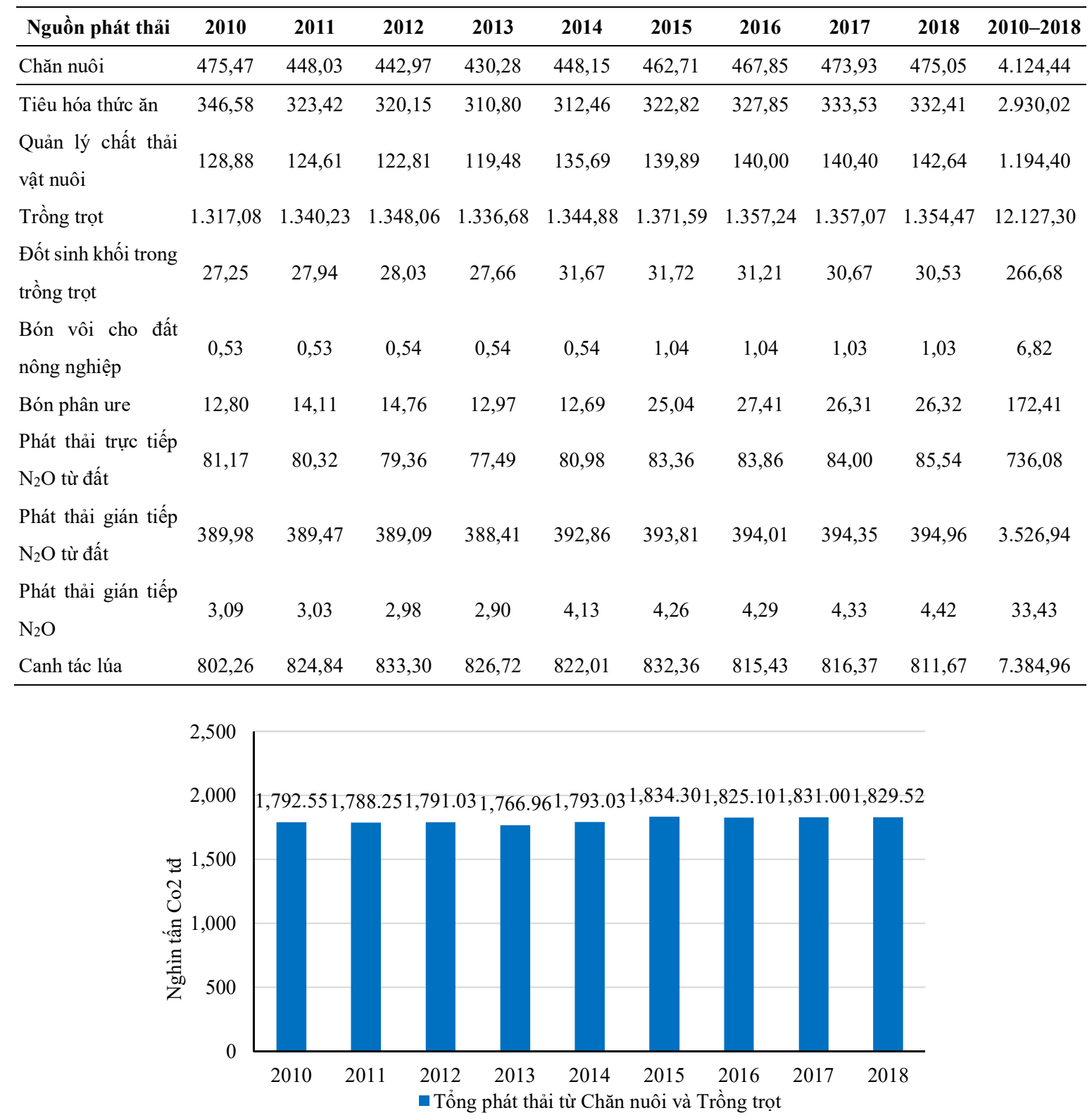

Hình 2. Xu thế phát thải khí nhà kính lĩnh vực Chăn nuôi và Trồng trọt giai đoạn 2010-2018 tỉnh Quảng Nam.

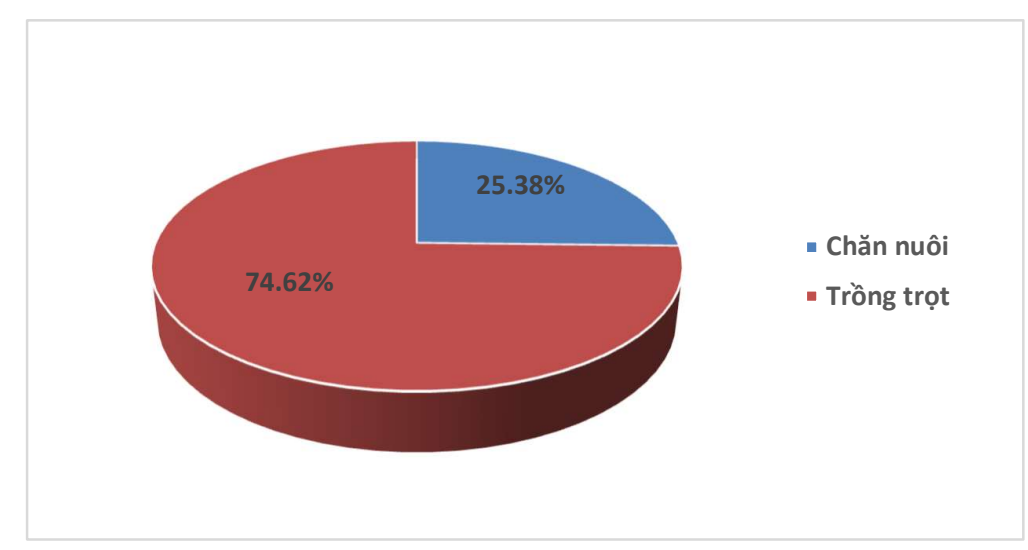


Hình 3. Cơ cấu phát thải khí nhà kính giai đoạn 2010-2018 tỉnh Quảng Nam.

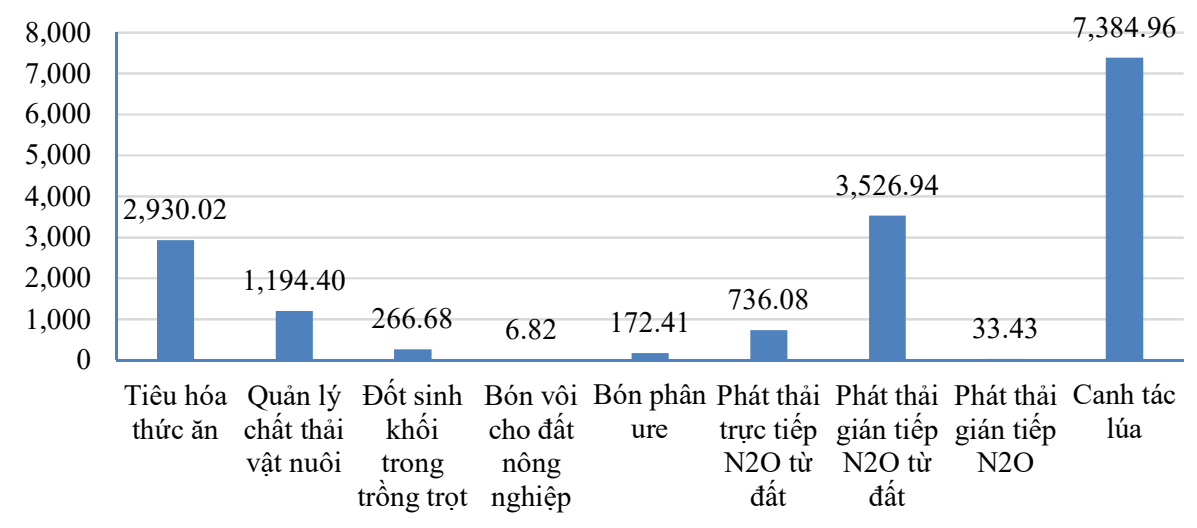

Hình 4. Tổng phát thải khí nhà kính theo tiểu lĩnh vực giai đoạn 2010-2018 tỉnh Quảng Nam.

\subsection{Phát thải khí nhà kính trong chăn nuôi tại Quảng Nam}

\subsubsection{Tiêu hóa thức ăn}

Phát thải khí nhà kính $\mathrm{CH}_{4}$ từ Tiêu hóa thức ăn trong giai đoạn 2010-2018 thay đổi không nhiều: $346,58 \mathrm{GgCO}_{2}$ tđ (năm 2010) và 332,41 $\mathrm{GgCO}_{2}$ tđ (năm 2018). Lượng phát thải khí nhà kính lớn nhất là $346,58 \mathrm{GgCO}_{2}$ tđ (năm 2010) và thấp nhất là $310,80 \mathrm{GgCO}_{2}$ tđ vào năm 2013. Theo cơ cấu phát thải của từng loại vật nuôi thì tổng phát thải giai đoạn 2010 2018 từ Bò có lượng phát thải cao nhất $\left(1.821,61 \mathrm{GgCO}_{2}\right.$ tđ) và phát thải thấp nhất là từ Ngựa $\left(0,24 \mathrm{GgCO}_{2} \mathrm{td}\right)$.

Bảng 4. Phát thải $\mathrm{CH}_{4}$ từ Tiêu hóa thức ăn giai đoạn 2010-2018.

\begin{tabular}{|c|c|c|c|c|c|c|c|c|c|}
\hline & & & & & & & & \multicolumn{2}{|c|}{ Đơn vị: $\mathrm{GgCO}_{2}$ tc } \\
\hline Vật nuôi & 2010 & 2011 & 2012 & 2013 & 2014 & 2015 & 2016 & 2017 & 2018 \\
\hline Bò & 206,74 & 197,14 & 195,03 & 188,71 & 191,08 & 199,24 & 207,27 & 214,64 & 221,75 \\
\hline Trâu & 122,28 & 109,34 & 108,42 & 107,18 & 106,57 & 108,26 & 106,41 & 105,95 & 97,02 \\
\hline Dê & 1,44 & 2,17 & 2,14 & 1,21 & 0,90 & 0,98 & 0,84 & 1,00 & 1,02 \\
\hline Ngựa & 0,04 & 0,04 & 0,02 & 0,03 & 0,02 & 0,02 & 0,02 & 0,02 & 0,03 \\
\hline Lợn & 16,09 & 14,73 & 14,55 & 13,67 & 13,89 & 14,31 & 13,31 & 11,91 & 12,59 \\
\hline Tổng & 346,58 & 323,42 & 320,15 & 310,80 & 312,46 & 322,82 & 327,85 & 333,53 & 332,41 \\
\hline
\end{tabular}

\subsubsection{Quản lý chất thải vật nuôi}

a. Phát thải $\mathrm{CH}_{4}$

Lượng phát thải khí nhà kính $\mathrm{CH}_{4}$ trong Quản lý chất thải vật nuôi lớn nhất là 93,27 $\mathrm{GgCO}_{2}$ tđ (năm 2018) và thấp nhất là $82,20 \mathrm{GgCO}_{2}$ tđ vào năm 2013 . Theo cơ cấu phát thải của từng loại vật nuôi thì tổng phát thải giai đoạn 2010-2018 từ Lợn có lượng phát thải cao nhất $\left(233,07 \mathrm{GgCO}_{2}\right.$ tđ) và phát thải thấp nhất là từ $\mathrm{Ngựa}\left(0,10 \mathrm{GgCO}_{2}\right.$ tđ) .

Bảng 5. Phát thải $\mathrm{CH}_{4}$ từ Quản lý chất thải vật nuôi giai đoạn 2010-2018.

Đơn vị: $\mathrm{GgCO}_{2}$ tđ

\begin{tabular}{llllllllll}
\hline Vật nuôi & 2010 & 2011 & 2012 & 2013 & 2014 & 2015 & 2016 & 2017 & 2018 \\
\hline
\end{tabular}




\begin{tabular}{cccccccccc}
\hline Vật nuôi & $\mathbf{2 0 1 0}$ & $\mathbf{2 0 1 1}$ & $\mathbf{2 0 1 2}$ & $\mathbf{2 0 1 3}$ & $\mathbf{2 0 1 4}$ & $\mathbf{2 0 1 5}$ & $\mathbf{2 0 1 6}$ & $\mathbf{2 0 1 7}$ & $\mathbf{2 0 1 8}$ \\
\hline Bò & 19,43 & 18,53 & 18,33 & 17,74 & 26,09 & 27,20 & 28,30 & 29,30 & 30,27 \\
Trâu & 25,70 & 22,98 & 22,79 & 22,53 & 21,69 & 22,04 & 21,66 & 21,57 & 19,75 \\
\hline Dê & 0,21 & 0,32 & 0,31 & 0,18 & 0,13 & 0,14 & 0,12 & 0,14 & 0,14 \\
Ngựa & 0,02 & 0,02 & 0,01 & 0,01 & 0,01 & 0,01 & 0,01 & 0,01 & 0,01 \\
Lợn & 30,50 & 27,92 & 27,58 & 25,91 & 25,48 & 26,27 & 24,43 & 21,87 & 23,12 \\
Gia cầm & 13,34 & 15,94 & 15,47 & 15,84 & 16,22 & 16,70 & 17,63 & 19,12 & 19,98 \\
Tổng & 89,19 & 85,70 & 84,48 & 82,20 & 89,62 & 92,35 & 92,14 & 92,00 & 93,27
\end{tabular}

b. Phát thải $\mathrm{N}_{2} \mathrm{O}$

Lượng phát thải khí nhà kính $\mathrm{N}_{2} \mathrm{O}$ trong Quản lý chất thải vật nuôi lớn nhất là 93,27 $\mathrm{GgCO}_{2}$ tđ (năm 2018) và thấp nhất là $82,20 \mathrm{GgCO}_{2}$ tđ̛ vào năm 2013 . Theo cơ cấu phát thải của từng loại vật nuôi thì tồng phát thải giai đoạn 2010-2018 từ Bò là cao nhất $(233,07$ $\mathrm{GgCO}_{2}$ tđ) và phát thải thấp nhất là từ Ngựa $\left(0,04 \mathrm{GgCO}_{2} \mathrm{tđ}\right)$.

\subsection{Phát thải khí nhà kính trong trồng trọt}

Tổng lượng phát thải khí nhà kính giai đoạn 2010-2018 trong lĩnh vực Trồng trọt là $12.127,30 \mathrm{GgCO}_{2}$ tđ. Lượng phát thải khí nhà kính lớn nhất là $1.371,59 \mathrm{GgCO}_{2}$ tđ (năm 2015) và nhỏ nhất là $1.317,08 \mathrm{GgCO}_{2}$ tđ vào năm 2010 . Theo cơ cấu phát thải thì tổng phát thải giai đoạn 2010-2018 từ canh tác lúa là cao nhất $\left(7.384,96 \mathrm{GgCO}_{2}\right.$ tđ) và phát thải thấp nhất là từ Bón vôi trong nông nghiệp $\left(6,82 \mathrm{GgCO}_{2} \mathrm{t}\right.$ đ).

Bảng 6. Phát thải khí nhà kính trong lĩnh vực Trồng trọt giai đoạn 2010-2018 tỉnh Quảng Nam.

\begin{tabular}{|c|c|c|c|c|c|c|c|c|c|c|}
\hline Nguồn phát thải & 2010 & 2011 & 2012 & 2013 & 2014 & 2015 & 2016 & 2017 & 2018 & $\begin{array}{c}2010- \\
2018\end{array}$ \\
\hline Tổng & $1.317,08$ & $1.340,23$ & $1.348,06$ & $1.336,68$ & $1.344,88$ & $1.371,59$ & $1.357,24$ & $1.357,07$ & $1.354,47$ & $12.127,30$ \\
\hline $\begin{array}{l}\text { Đốt sinh khối } \\
\text { trong trồng trọt }\end{array}$ & 27,25 & 27,94 & 28,03 & 27,66 & 31,67 & 31,72 & 31,21 & 30,67 & 30,53 & 266,68 \\
\hline $\begin{array}{l}\text { Bón vôi cho đất } \\
\text { nông nghiệp }\end{array}$ & 0,53 & 0,53 & 0,54 & 0,54 & 0,54 & 1,04 & 1,04 & 1,03 & 1,03 & 6,82 \\
\hline Bón phân ure & 12,80 & 14,11 & 14,76 & 12,97 & 12,69 & 25,04 & 27,41 & 26,31 & 26,32 & 172,41 \\
\hline $\begin{array}{l}\text { Phát thải trực tiếp } \\
\mathrm{N}_{2} \mathrm{O} \text { từ đất }\end{array}$ & 81,17 & 80,32 & 79,36 & 77,49 & 80,98 & 83,36 & 83,86 & 84,00 & 85,54 & 736,08 \\
\hline $\begin{array}{l}\text { Phát thải gián } \\
\text { tiếp } \mathrm{N}_{2} \mathrm{O} \text { từ đất }\end{array}$ & 389,98 & 389,47 & 389,09 & 388,41 & 392,86 & 393,81 & 394,01 & 394,35 & 394,96 & $3.526,94$ \\
\hline $\begin{array}{l}\text { Phát thải gián } \\
\text { tiếp } \mathrm{N}_{2} \mathrm{O}\end{array}$ & 3,09 & 3,03 & 2,98 & 2,90 & 4,13 & 4,26 & 4,29 & 4,33 & 4,42 & 33,43 \\
\hline Canh tác lúa & 802,26 & 824,84 & 833,30 & 826,72 & 822,01 & 832,36 & 815,43 & 816,37 & 811,67 & $7.384,96$ \\
\hline
\end{tabular}

\subsection{1. Đốt sinh khối trong trồng trọt}

Tổng lượng phát thải khí nhà kính giai đoạn 2010-2018 trong tiểu lĩnh vực Đốt sinh khối trong trồng trọt là $266,68 \mathrm{GgCO}_{2}$ tđ. Lượng phát thải khí nhà kính lớn nhất là $31,72 \mathrm{GgCO}_{2}$ tđ (năm 2015) và nhỏ nhất là $27,25 \mathrm{GgCO}_{2}$ tđ vào năm 2010.

\subsubsection{Bón vôi cho đất nông nghiệp}


Tổng lượng phát thải khí nhà kính giai đoạn 2010-2018 trong tiểu lĩnh vực Bón vôi cho đất nông nghiệp là $6,82 \mathrm{GgCO}_{2}$ tđ. Lượng phát thải khí nhà kính lớn nhất là $1,04 \mathrm{GgCO}_{2}$ tđ (năm 2015) và nhỏ nhất là $0,53 \mathrm{GgCO}_{2}$ tđ vào năm 2010 .

\subsubsection{Bón vôi cho đất nông nghiệp}

Tổng lượng phát thải khí nhà kính giai đoạn 2010-2018 trong tiểu lĩnh vực Bón phân ure là $172,41 \mathrm{GgCO}_{2}$ tđ. Lượng phát thải khí nhà kính lớn nhất là $27,41 \mathrm{GgCO}_{2}$ tđ̛ (năm 2016) và nhỏ nhất là 12,69 $\mathrm{GgCO}_{2}$ tđ vào năm 2014 .

\subsubsection{Phát thải trực tiếp $\mathrm{N}_{2} \mathrm{O}$ từ đất}

Tổng lượng phát thải khí nhà kính giai đoạn 2010-2018 trong tiểu lĩnh vực Phát thải trực tiếp $\mathrm{N}_{2} \mathrm{O}$ từ đất là $172,41 \mathrm{GgCO}_{2}$ tđ. Lượng phát thải khí nhà kính lớn nhất là $27,41 \mathrm{GgCO}_{2}$ tđ (năm 2016) và nhỏ nhất là 12,69 $\mathrm{GgCO}_{2}$ tđ vào năm 2014 .

\subsubsection{Phát thải gián tiếp $\mathrm{N}_{2} \mathrm{O}$ từ đất}

Tổng lượng phát thải khí nhà kính giai đoạn 2010-2018 trong tiểu lĩnh vực Phát thải gián tiếp $\mathrm{N}_{2} \mathrm{O}$ từ đất là $3.526,94 \mathrm{GgCO}_{2}$ tđ. Lượng phát thải khí nhà kính lớn nhất là 394,96 $\mathrm{GgCO}_{2}$ tđ (năm 2018) và nhỏ nhất là $388,41 \mathrm{GgCO}_{2}$ tđ vào năm 2013.

\subsubsection{Phát thải gián tiếp $\mathrm{N}_{2} \mathrm{O}$ Quản lý chất thải vật nuôi}

Tổng lượng phát thải khí nhà kính giai đoạn 2010-2018 trong tiểu lĩnh vực Phát thải gián tiếp $\mathrm{N}_{2} \mathrm{O}$ Quản lý chất thải vật nuôi là $33,43 \mathrm{GgCO}_{2}$ tđ. Lượng phát thải khí nhà kính lớn nhất là 4,42 $\mathrm{GgCO}_{2}$ tđ (năm 2018) và nhỏ nhất là $2,9 \mathrm{GgCO}_{2}$ tđ vào năm 2013.

\subsubsection{Canh tác lúa}

Tổng lượng phát thải khí nhà kính giai đoạn 2010-2018 trong tiểu lĩnh vực Canh tác lúa là 7.384,96 $\mathrm{GgCO}_{2}$ tđ. Lượng phát thải khí nhà kính lớn nhất là 833,3 $\mathrm{GgCO}_{2}$ tđđ (năm 2012) và nhỏ nhất là $802,26 \mathrm{GgCO}_{2}$ tđ vào năm 2010 .

\section{Kết luận}

Qua kiểm kê phát thải khí nhà kính trong lĩnh vực trong lĩnh vực chăn nuôi và trồng trọt (không bao gồm phát thải và hấp thụ từ đất, cũng như đốt sinh khối từ đất rừng và chuyển đổi sử dụng của đất rừng) giai đoạn 2010-2018 nhận thấy lượng phát thải lớn nhất là phát thải $\mathrm{CH}_{4}$ từ canh tác lúa và phát thải lớn thứ hai là phát thải $\mathrm{CH}_{4}$ và $\mathrm{N}_{2} \mathrm{O}$ từ chăn nuôi (tiêu hóa thức ăn và quản lý chất thải). Đây là xu thế phát thải điển hình của các tỉnh có kinh tế nông nghiệp chiếm tỷ trọng chủ yếu (với diện tích trồng lúa và số lượng vật nuôi lớn). Việc kiểm kê phát thải khí nhà kính trong một giai đoạn dài (2010-2018) giúp các nhà quản lý, các chuyên gia đánh giá được các nguồn phát thải chính từ đó đề ra các giải phát giảm nhẹ phát thải khí nhà kính phù hợp với điều kiện địa phương, hướng đến mục tiêu phát triển xanh, bền vững, bảo vệ môi trường, chống biến đổi khí hậu.

Đóng góp cho nghiên cứu: Xây dựng ý tưởng nghiên cứu: L.A.N., N.T.L.; Lựa chọn phương pháp nghiên cứu: L.A.N., P.D.A., P.T.L., N.T.L., D.Q.T.; Xử lý số liệu: P.A.D., L.A.N.; Thu thập, phân tích, xử lý số liệu: P.A.D., L.A.N.; Viết bản thảo bài báo: L.A.N., P.A.D., N.T.L.; Chỉnh sửa bài báo: N.T.L., D.Q.T.

Lời cảm ơn: Nghiên cứu này được thực hiện trong khuôn khổ của đề tài khoa học công nghệ cấp quốc gia "Nghiên cứu đề xuất hệ thống giám sát-báo cáo-thẩm định $(\mathrm{MRV})$ các hoạt động ứng phó với biến đổi khí hậu ở Việt Nam”, mã số BĐKH.32/16-20 thuộc Chương trình Khoa học và Công nghệ ứng phó với Biến đổi khí hậu, Quản lý tài nguyên và môi trường giai đoạn 2016-2020, mã số BĐKH/16-20. 
Lời cam đoan: Tập thể tác giả cam đoan bài báo này là công trình nghiên cứu của tập thể tác giả, chưa được công bố ở đâu, không được sao chép từ những nghiên cứu trước đây; không có sự tranh chấp lợi ích trong nhóm tác giả.

Tài liệu tham khảo

1. Hướng dẫn kiểm kê quốc gia khí nhà kính 2006. Ủy ban Liên chính phủ về biến đổi khí hậu, 2006.

2. https://iopscience.iop.org/article/10.1088/1755-1315/372/1/012044/meta, Estimation of Greenhouse Gas (GHG) Emission from Livestock Sector by Using ALU Tool: West Java Case Study, 2019.

3. https://iopscience.iop.org/article/10.1088/1748-9326/8/1/015030/meta, Advancing national greenhouse gas inventories for agriculture in developing countries: improving activity data, emission factors and software technology

4. https://ghgprotocol.org/greenhouse-gas-protocol-accounting-reporting-standard-citi es.

5. Sở Tài nguyên và Môi trường thành phố Hà Nội. Kế hoạch hành động ứng phó biến đổi khí hậu, 2017.

6. Sở Tài nguyên và Môi trường thành phố Đà Nẵng. Kế hoạch hành động ứng phó biến đổi khí hậu trên địa bàn thành phố Đà Nẵng, 2013.

7. Cơ quan Hợp tác Quốc tế Nhật Bản (JICA). Tài liệu hướng dẫn kiểm kê khí nhà kính cấp thành phố, 2017.

8. Sở Tài nguyên và Môi trường thành phố Hồ Chí Minh. Hỗ trợ lên kế hoạch và thực hiện các hành động giảm nhẹ phát thải khí nhà kính phù hợp với điều kiện quốc gia, 2019.

9. Tổng cục Thống kê. Niên giám thống kê năm 2010-2018, 2011-2019.

10. Cục Thống kê tỉnh Quảng Nam. Niên giám thống kê 2010-2018, 2011-2019.

11. Bộ Nông nghiệp và Phát triển Nông thôn. Niên giám thống kê ngành Nông nghiệp và Phát triên Nông thôn năm 2010-2015, 2016.

12. Bộ Nông nghiệp và Phát triển Nông thôn. Niên giám thống kê ngành Nông nghiệp và Phát triên Nông thôn năm 2016-2018, 2019.

13. Bộ Nông nghiệp và Phát triển Nông thôn. Niên giám thống kê ngành Nông nghiệp và Phát triên Nông thôn năm 2016.

14. Tổ chức Nông nghiệp và Lương thực thế giới (FAO). Tổ chức Thống kê của FAO (FAOSTAT), http://faostat.fao.org/.

\title{
Greenhouse GAS emission in agricultural sector in Quang Nam province in the period of 2010-2018
}

\author{
Ngoc Le Anh' ${ }^{1}$, An Pham Duc ${ }^{1}$, Long Pham Thanh ${ }^{1 *}$, Nguyen Thi Lieu², Doan Quang \\ $\mathrm{Tri}^{3}$ \\ ${ }^{1}$ Sub-Institute of Hydrometeorology and Climate Change; \\ leanhngoc.sihymete@gmail.com; phamthanhlong559@gmail.com \\ ${ }^{2}$ Institute of Hydrometeorology and Climate Change; lieuminh2011@gmail.com \\ ${ }^{3}$ Vietnam Journal of Hydrometeorology, Viet Nam Meteorological and Hydrological \\ Administration; doanquangtrikttv@gmail.com
}

\begin{abstract}
The paper presents the calculation results of greenhouse gas emissions in Quang Nam Province for the agricultural sector including the sub-sectors of cultivation, livestock and crop sector in aquaculture in the period 2010-2018 based on the guidelines of the Intergovernmental Panel on Climate Change for GHG inventory and application of ALU software. Accordingly, the total greenhouse gas emissions in the agriculture sector of Quang Nam province in the period 2010-2018 reached 9,410.6 $\mathrm{GgCO}_{2}$ eq and tended to decrease from $1,086.1 \mathrm{GgCO}_{2} \mathrm{eq}(2010)$ to $1033.5 \mathrm{GgCO}_{2} \mathrm{eq}(2018)$. In terms of structure, emissions in the cultivation subsector accounted for the highest proportion $(52.6 \%)$, the second ranked was livestock husbandry $(47.4 \%)$.
\end{abstract}

Keywords: Greenhouse gas; Agriculture; ALU software; IPCC. 